\title{
Inhibiting fly ash reactivity by adding N- and S-
}

\section{containing compounds}

Aurora Soler*, Juan A. Conesa, Nuria Ortuño

*Email: aurorasoler.guillen@ua.es

\section{ABSTRACT}

8 The inhibitory effect of thiourea (TUA), ammonium thiosulfate (TSA) and amidosulfonic acid (ASA) on the

9 reactivity of fly ash air was investigated using a thermobalance at different heating rates $\left(5,10\right.$ and $20 \mathrm{~K} \mathrm{~min}^{-}$

$10{ }^{1}$ ). A model fly ash (activated carbon $+50 \mathrm{wt} . \% \mathrm{CuCl}_{2} \cdot 2 \mathrm{H}_{2} \mathrm{O}$, pyrolyzed at $700{ }^{\circ} \mathrm{C}$ and washed) was used as

11 carbonaceous material. Adding $\mathrm{CuCl}_{2} \cdot 2 \mathrm{H}_{2} \mathrm{O}$ to the activated carbon led to an increased rate of decomposition with the air's oxygen. TUA and TSA behaved in a similar way, accelerating the decomposition of the model fly ash. ASA also accelerated the decomposition but to a lower extent. We postulate that the increase in decomposition rate is caused by a reaction between carbonaceous material and $\mathrm{N}$ - and S-containing compounds. The formation of nitrogenated and sulphured compounds was confirmed by TG-MS. A kinetic model based on a single reaction of order 0.6 showed very good correlations with all the heating rates tested in oxidant atmosphere.

Keywords: inhibition, thiourea, ammonium thiosulfate, amidosulfonic acid, model ash, thermogravimetry. 
Municipal solid waste (MSW) - more commonly known as garbage - consists of every item humans use in their homes, hospitals, schools and businesses, and then throw away. MSW represents around $10 \%$ of total waste generated worldwide (Eurostat, 2018).

Despite the fact that MSW generation in Europe has slowed down and stabilized at about $520 \mathrm{~kg}$ per capita since 2002 (Blumenthal, 2011), the volume of landfilled MSW continues to grow. Waste disposal can cause different impacts on the environment, including pollution of air, surface and water; moreover, it can present a risk to public health (Eurostat, 2010). Therefore, sound waste management is needed to protect the environment and public health, as well as to reduce demand for natural resources. In recent years, processes with low impacts on the environment and based on thermochemical methods, allowing to produce energy from waste, have developed and played a major role (Conesa et al., 2001).

Conventional processes consist in MSW incineration, generating three potential sources of exposure to different pollutants: solid residues (bottom and fly ashes), cooling water and atmospheric emissions (fine particles and toxic pollutants). Fine particles generated in the combustion can have negative effects on human health due to their size and composition (Laden et al., 2000; Morawska and Zhang, 2002). In combustion processes, chlorinated organic pollutants, including polychlorinated dibenzo-p-dioxins and dibenzofurans (PCDD/Fs), can be released into the atmosphere (Baker and Hites, 2000; Ricketts et al., 2002; Jedynska et al., 2014) because residual organic carbon and high-molecular-weight compounds from incomplete combustion can result in precursor materials for de novo synthesis.

As reported by Vogg and Stieglitz (1986), PCDD/Fs were directly formed outside the combustion zone from carbonaceous materials, such as soot and chlorine, in the presence of volatile metals contained in the ash, which catalysed the process (e.g. copper, zinc and aluminium) at temperatures ranging from 200 to $400{ }^{\circ} \mathrm{C}$. Based on a previous study by Stieglitz et al. (1989b), two consecutive reactions occurred: (1) The metal-ion catalysed transfer of chloride (halide) to the macromolecular structure of carbon with the formation of carbonhalide bonds and (2) the degradation of the macromolecular structure of the carbon in presence of oxygen and metal-ions as catalyst of $\mathrm{CO}_{2}$ and volatile chlorinated aromatic compounds. 
45 Therefore, thermal facilities require technologies that inhibit the formation of chlorinated aromatic compounds so as to reduce their emission and thus prevent toxic and detrimental environmental effects. Numerous reduction methods have been tested, e.g. photocatalytic decomposition, catalytic and as well as ozone oxidation, etc. (Lu et al., 2011; Lu et al., 2012; Ji et al., 2013). However, chemical inhibition is the most promising method to prevent the formation of chlorinated aromatic compounds. The inhibiting compounds used in the reaction must be efficient, non-toxic, inexpensive and environment-friendly; they must also remain active for as long as required to supress the formation of chlorinated aromatic compounds (Ruokojärvi et al., 2001).

The ability to reduce PCDD/F formation of various inhibitors has been object of extensive research. Pandelova et al. (2005) and Wielgosinski et al. (2016) studied the suppression of PCDD/F formation using different inhibitors divided into four subgroups: metal oxides, N-compounds, S-compounds and N- and Scompounds, the latter being the most effective inhibitors. Fu et al. (2015) and Zhan et al. (2016b) tested the inhibitory capacity of thiourea (TUA), amidosulfonic acid (ASA) as well as ammonium thiosulfate (TSA) and concluded that TUA had the highest inhibition efficiency. Fujimori et al. (2016) investigated the inhibitory effects and mechanisms of TUA during the formation of chloroaromatic compounds in MSW fly ash. Samaras et al. (2000) obtained that a 1 wt.\% of ASA was sufficient to prevent $96 \%$ of PCDD/F emission. Kuzuhara et al. (2005) found that formation of PCDD/F decreased significantly upon addition of ammonia or urea, suggesting that this suppression was caused by the competing reaction between organic compounds with $\mathrm{NH}$. and $\mathrm{CN}$ radicals. Nitrogen and sulfur contain free pairs of electrons making them capable of forming stable catalytic complexes with metals, delaying catalyst activity, while the ammonia compound decreases the concentration of hydrogen chloride, which is involved in the formation of PCDD/Fs (Ooi et al., 2011).

Despite the large number of studies on the reduction of PCDD/F formation using inhibiting compounds, no research was found in the literature on the inhibitory effect of $\mathrm{N}$ - and S-containing compounds on reactivity of fly ash in thermobalance. Therefore, the aim of this study was to examine the effect of TUA, TSA and ASA on the oxidative decomposition of model fly ash and to propose a valid kinetic model. Evolved gas products were also examined.

\section{Materials and methods}


73 An activated carbon (AC) supplied by Merck with a very low chloride content was used in this study.

74 Elemental analysis (98.72 wt.\% C, 0.70 wt.\% $\mathrm{H}$ and 0.58 wt.\% O and ash) was carried out in a Thermo 75 Finnigan Flash 1112 Series Elemental Analyser. The concentration of chlorine was measured using the US EPA Methods 5050 (US EPA, 1994) and 9056A (US EPA, 2000) by oxygen combustion bomb-ion chromatography (Dionex DX-500), the average value of two duplicates being $0.03 \mathrm{wt} . \%$.

AC was mixed with $\mathrm{CuCl}_{2} \cdot 2 \mathrm{H}_{2} \mathrm{O}$ in a proportion $\mathrm{CuCl}_{2} \cdot 2 \mathrm{H}_{2} \mathrm{O} /$ activated carbon $=1 \mathrm{~g} \cdot \mathrm{g}^{-1}$. This proportion was selected based on a previous study by Stieglitz (1998), who analysed the effect of several halides in different proportions.

This mixture was pyrolyzed in a tubular reactor, which consisted in a quartz tube (80 $\mathrm{mm}$ internal diameter) located inside a horizontal furnace, at $700{ }^{\circ} \mathrm{C}$ for $17 \mathrm{~min}(1000 \mathrm{~s})$, in a similar way to that used in previous studies (Conesa et al., 2001; Conesa et al., 2002; Ortuño et al., 2014), and then washed with an acidified nitrate solution to remove $\mathrm{CuCl}_{2}$ excess. To do this, $2 \mathrm{~g}$ of the material was mixed with $1 \mathrm{~L}$ of nitrate solution solution $\left(0.01 \mathrm{~mol} / \mathrm{L} \mathrm{NaNO}_{3}\right.$ acidified with $\left.\mathrm{HNO}_{3}\right)$ and was left to dry at room temperature. This procedure yields a material that presents copper chloride chemically bonded to the structure of the carbon, as was already pointed out in a previous study (Conesa et al., 2001).

The resulting material (model ash 'MA') was characterized, and the results of its composition were 89.69 wt.\% C, 0.87 wt.\% $\mathrm{H}$ and 9.44 wt.\% O and ash. The concentration of other elements (2.21 wt.\% O, 0.18 wt.\% $\mathrm{Si}, 0.18$ wt.\% $\mathrm{Cl}$ and $6.50 \mathrm{wt} . \% \mathrm{Cu})$ was measured using a sequential $\mathrm{X}$-ray fluorescence spectrometer (Philips Magix Pro PW2400). In addition, this material was characterized in the thermobalance, and no 94 interferences were found from the decomposition of $\mathrm{CuCl}_{2}$.

Three different inhibiting compounds were examined for their capacity to reduce PCDD/F formation: TUA, TSA and ASA; all of them were applied in a concentration of 3 wt.\% of the total sample amount. These inhibiting compounds were added to the MA by adding an aqueous solution of the corresponding inhibitor at 
room temperature, followed by a drying stage with stirring at $70^{\circ} \mathrm{C}$. Worthy of note, the addition of inhibitors in the solid phase was also tested but it was discarded because it did not give rise to sufficiently homogeneous samples.

\subsection{Thermogravimetric analysis (TGA)}

The TGA was performed on a Perkin Elmer thermogravimetric analyser (model STA6000). The samples were subjected to three different heating rates $\left(5,10\right.$ and $\left.20{ }^{\circ} \mathrm{C} \mathrm{min}^{-1}\right)$ from room temperature up to $950{ }^{\circ} \mathrm{C}$ in an oxidizing atmosphere. The flow rate of the carrier gas (synthetic air) was set at $100 \mathrm{~mL} \mathrm{~min}^{-1}$. For each run, approximately $8 \mathrm{mg}$ of sample was weighed.

Prior to each experiment, a blank run was performed under the same experimental conditions but using an empty crucible. Subsequently, for baseline correction, the weight values recorded for each experimental time were subtracted from the values obtained in the TG runs with the sample.

109 Duplicated runs were carried out in the thermobalance to check the reproducibility of the equipment. 110 Acceptable reproducibility was obtained for the decomposition of all the samples.

111 Following the recommendations found in specialized literature (Conesa and Soler, 2017), runs performed at 112 different heating rates were correlated simultaneously for kinetic study, in order to obtain one single set of 113 parameters for each sample.

\section{2.3. Thermogravimetry coupled to mass spectrometric analysis (TG-MS)}

115 To characterize the compounds evolved during TG runs, a Mettler Toledo thermobalance (model TGA/SDTA851e/LF/1600) coupled to a Pfeiffer Vacuum mass spectrometer (model Thermostar GSD301T) was used, operating in SIR mode and with electron impact ionization at $70 \mathrm{eV}$. Approximately $8 \mathrm{mg}$ of sample was heated with a constant heating rate of $20^{\circ} \mathrm{C} \mathrm{min}^{-1}$ from room temperature to $950{ }^{\circ} \mathrm{C}$ in helium atmosphere.

119 The flow rate of carrier gas $(\mathrm{He})$ was set at $100 \mathrm{~mL} \mathrm{~min}^{-1}$. Other heating rates were not tested because the concentration of the evolved gas was not enough to be detected.

\section{Results and discussion}

\subsection{Thermal decomposition of the inhibiting compounds}


123 Prior to studying the effect of the inhibitors in the thermal decomposition of the activated carbon and model 124 ash samples, TG runs were performed to study the evolution of weight according to temperature for pure 125 TUA, ASA and TSA. Fig. 1 shows the results for the different heating rates tested (5, 10 and $\left.20^{\circ} \mathrm{C} / \mathrm{min}\right)$. All 126 three compounds lost weight in the temperature range $150-450{ }^{\circ} \mathrm{C}$, but TSA and TUA lost weight much faster 127 than ASA. It is important to note that the weight losses of these three compounds could be due to both 128 evaporation (vapour formed by molecules of the same nature) and to thermal decomposition (formation of 129 other volatile species). In this sense, Wang et al. (2005) studied TUA decomposition and pointed out that TUA 130 decomposed in carbon disulfide, isothiocyanic acid and ammonia at 187.5 - $246.2^{\circ} \mathrm{C}$. Zhan et al. (2016a) 131 confirmed that TUA decomposition set at temperatures of ca. $180{ }^{\circ} \mathrm{C}$ and its residual weight declined fast 132 between $200-250{ }^{\circ} \mathrm{C}$, in accordance with the study by Wang et al. (2005). Based on these studies, Fujimori et 133 al. (2016) concluded that thermal decomposition products from TUA showed a potential to inhibit chlorinated 134 compound formation.
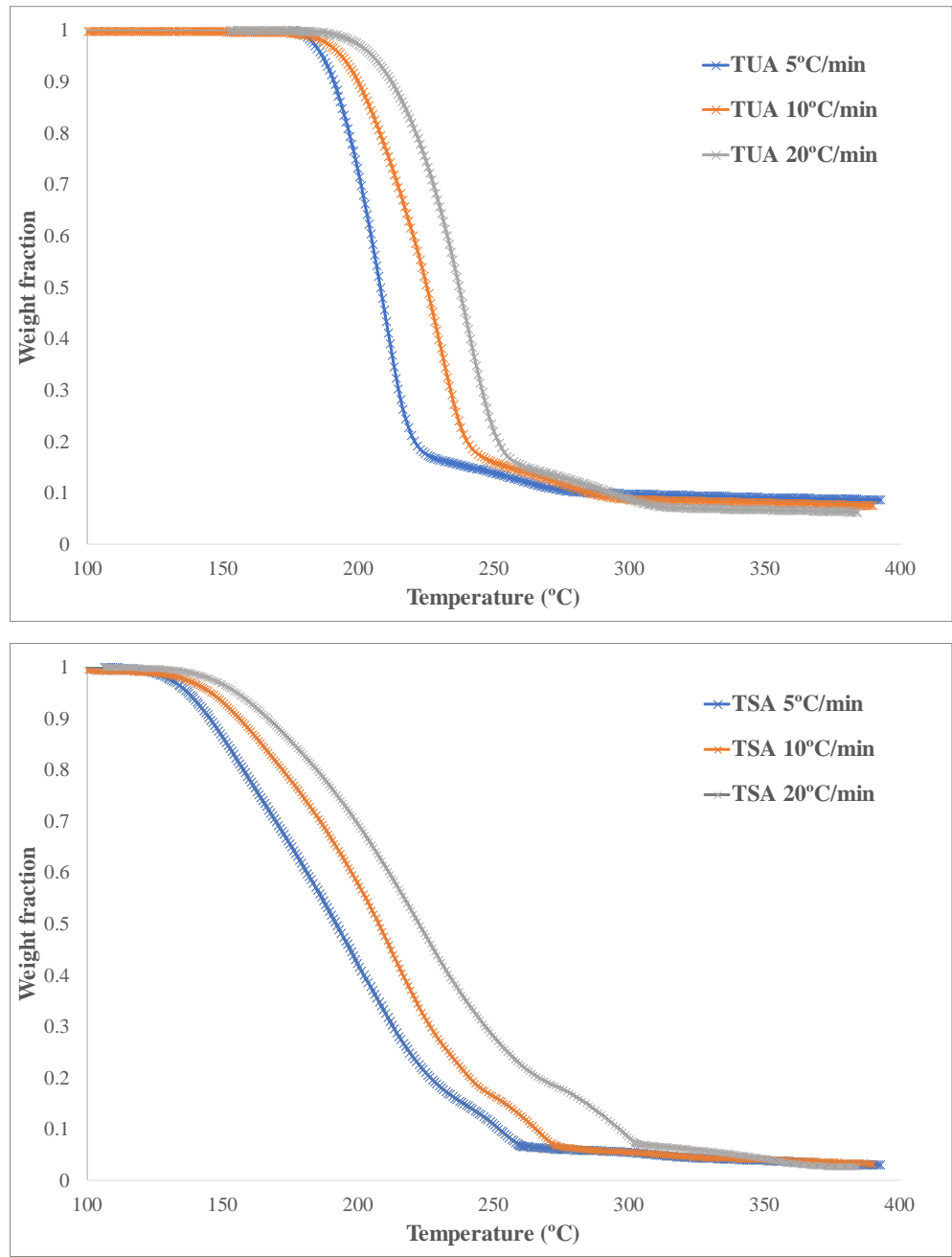


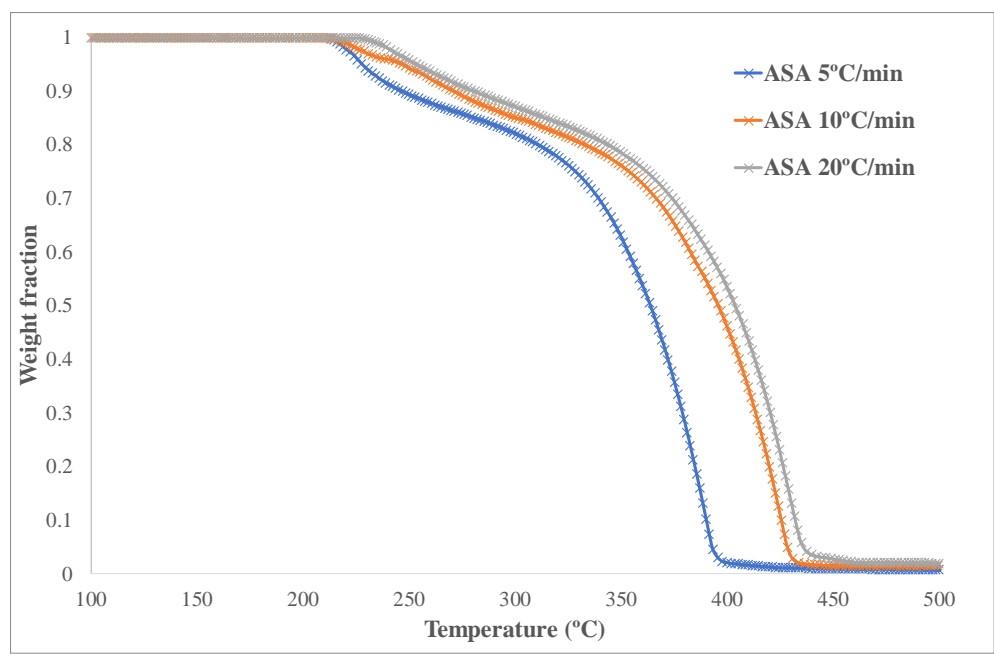

138 Fig. 1. Thermal decomposition of the compounds used as inhibitors for PCDD/F formation: thiourea (TUA), 139 ammonium thiosulfate (TSA) and amidosulfonic acid (ASA) at three different heating rates (5, 10 and $20{ }^{\circ} \mathrm{C}$ $140 \min ^{-1}$ ) in synthetic air.

141 Based on the TG curves for TSA decomposition (see Fig. 1), it is possible to conclude that its decomposition 142 takes place in two steps. TSA begins to decompose upon heating above $150{ }^{\circ} \mathrm{C}$, initially forming ammonium 143 sulfate and resulting in ammonia, nitrogen, sulfur oxides and water when heating at higher temperatures (290 $144{ }^{\circ} \mathrm{C}$ approx.) (Liu Ke-wei, 2002). Fu et al. (2015) indicated that ammonium $\left(\mathrm{NH}_{4}{ }^{+}\right)$contained in TSA tended to 145 inhibit PCDD/F formation when released in the form of $\mathrm{NH}_{3}$.

146 ASA, just like TSA, decomposes into oxidation products when heated, and thus the sulfur and nitrogen 147 contained are converted into $\mathrm{SO}_{2} / \mathrm{SO}_{3}$ and ammonia, respectively. Samaras et al. (2000) concluded that the 148 addition of 1 wt.\% ASA to an artificial refuse derived fuel, before the combustion experiment, reduced the 149 PCDD/F emissions by more than $95 \%$ in combustion runs at $200{ }^{\circ} \mathrm{C}$.

\section{3.2. Effect of $\mathbf{C u C l}_{2}$ and inhibitors on thermal decomposition of model ash}

151 Three dynamic experiments in synthetic air $\left(4: 1 \mathrm{~N}_{2} / \mathrm{O}_{2}\right)$ were carried out at room temperature up to $950{ }^{\circ} \mathrm{C}$ at 152 different heating rates $\left(5,10\right.$ and $\left.20^{\circ} \mathrm{C} \mathrm{min}^{-1}\right)$ for each sample studied. Fig. 2 presents the experimental weight 153 loss variation according to temperature in dynamic experiments. In all TG curves, the weight fraction is 154 defined as the ratio between solid mass at any time and initial solid mass.

155 Fig. 2 shows that, as expected, the mass loss curves for each material moved to the right (higher temperatures) 156 when the heating rate increased. This behaviour has been highlighted by other authors, who have put forward 
a variety of explanations; the sole consideration of kinetic law, however, should be enough to explain this

158 behaviour (Caballero and Conesa, 2005; Conesa and Rey, 2015). Despite the shift observed in TG curves 159 according to heating rates, the pattern of thermal degradation did not change: the same residue was obtained at 160 different heating rates for each material. Furthermore, in many cases, the curves show a decrease in 161 temperature in the later part of the runs: this is due to the fact that the temperature used for plotting the results 162 was not the programmed temperature, but that measured by the thermocouple which was very close to that of 163 the sample. In the presence of oxygen, given the high exothermicity of the combustion reactions, a sharp 164 temperature increase may occur, the temperature inside the sample becoming considerably higher than that 165 foreseen by the assigned program. This temperature increase is offset by the control of the thermobalance to 166 the point that even the sample is slightly cooled, as reflected in the TG curves.
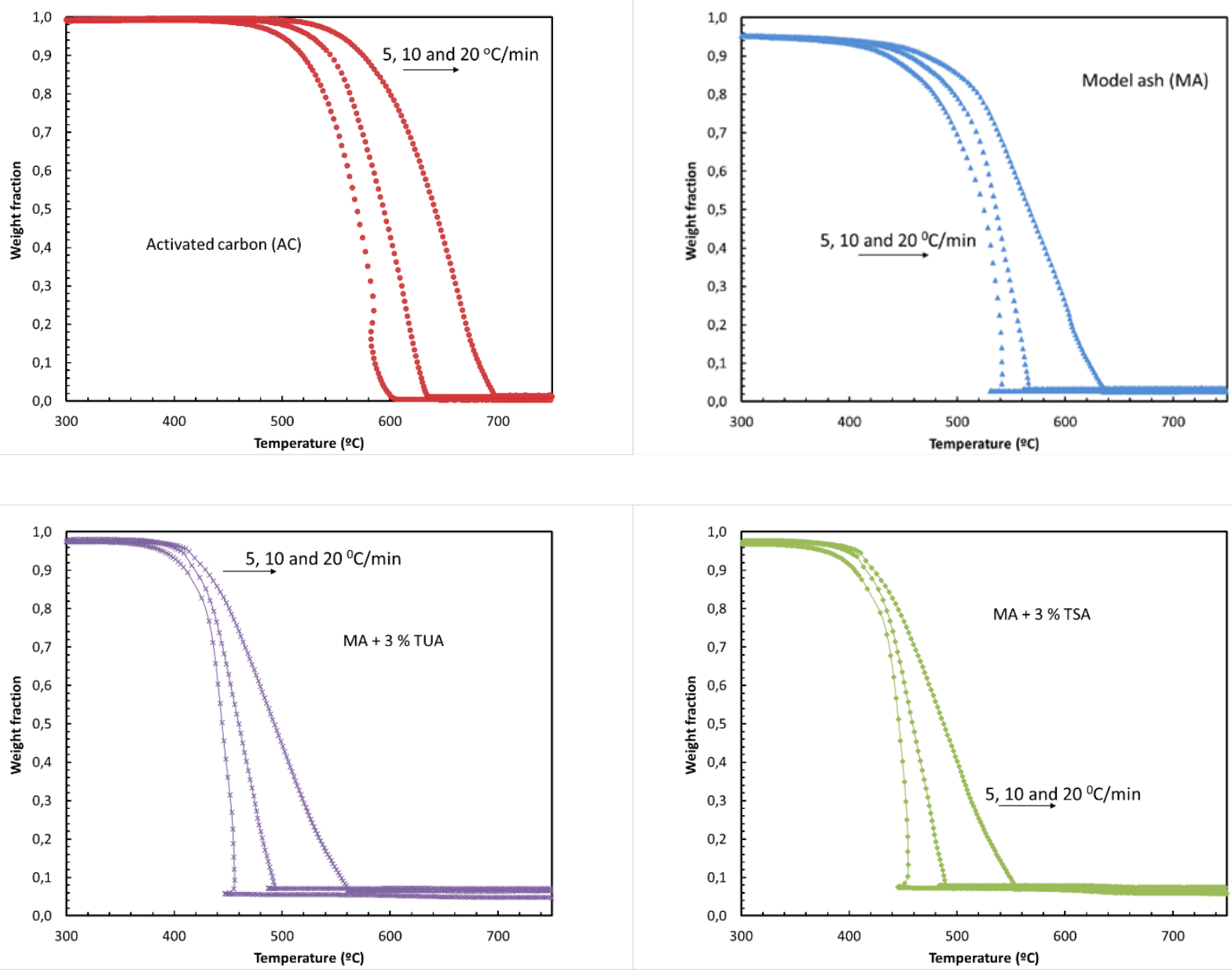


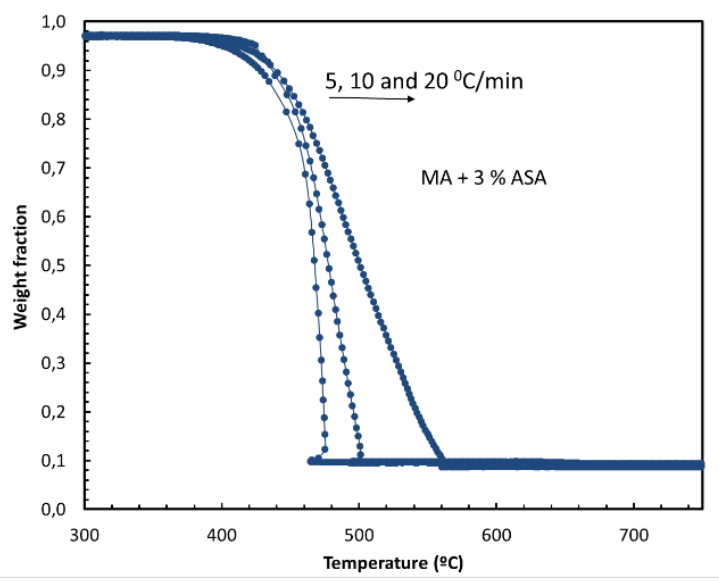

168 Fig. 2. Thermal decomposition of activated carbon (AC), model ash (MA) and mixtures of MA with 3 wt \% 169 TUA, TSA and ASA, respectively, at 5, 10 and $20^{\circ} \mathrm{C} \mathrm{min}^{-1}$ in synthetic air.

170 A run mixing AC with TUA was also carried out (not shown in the Figures), to check whether there was a 171 possible interaction; the decomposition of carbonaceous material was not influenced, however, by the 172 presence of the inhibitor at any of the studied heating rates. This indicates that the interaction was mediated by 173 the $\mathrm{CuCl}_{2}$ present in the MA or at least that the presence of $\mathrm{C}-\mathrm{Cl}$ bonds was necessary.

174 For a better comparison, Fig. 3 shows the TG curves corresponding to the degradation runs at $5{ }^{\circ} \mathrm{C} \min ^{-1}$. The 175 maximum mass loss rate -commonly used in the literature to characterize char reactivity- occurred at different 176 temperatures for the different samples. The addition of $\mathrm{CuCl}_{2}$ accelerated thermal decomposition (i.e. the MA 177 curve was found to be at lower temperatures compared to the AC curve), in such a way that a temperature 178 reduction of a maximum decomposition rate of almost $55{ }^{\circ} \mathrm{C}$ was observed for MA. The presence of traces of copper and other metals has been found to catalyse the oxidative degradation process of materials such as AC.

180 In this way, several authors (Stieglitz et al., 1989a; Luijk et al., 1994; Stieglitz, 1998) proved the accelerating 181 effect of the presence of metal chlorides, acting as catalysts in the decomposition of AC. It has also been pointed out that the catalytic effect of the addition of $\mathrm{CuCl}_{2}$ to the oxidative degradation of different materials depends on the characteristics of the material itself. Carbon 'quality' (i.e. \% of carbon and surface area of the particles) plays an important role, as well as the presence of chloride in the composition of the starting material (Conesa et al., 2001). Conesa et al. (2002) indicated that copper (II) ion is not uniquely responsible 186 for the change in carbon reactivity, the presence of a halogen is also necessary to promote thermal 
decomposition. According to Schwartz and Stieglitz (1992), oxidative carbon degradation producing $\mathrm{CO}_{2}$ occurs at $700{ }^{\circ} \mathrm{C}$ without catalyst and at $345{ }^{\circ} \mathrm{C}$ if traces of copper (II) ions are present, but always using chlorinated metals. Tuppurainen et al. (1998) indicated that the highest PCDD/F formation rates occurred in the presence of $\mathrm{HCl}$ and traces of $\mathrm{CuCl}_{2}$.

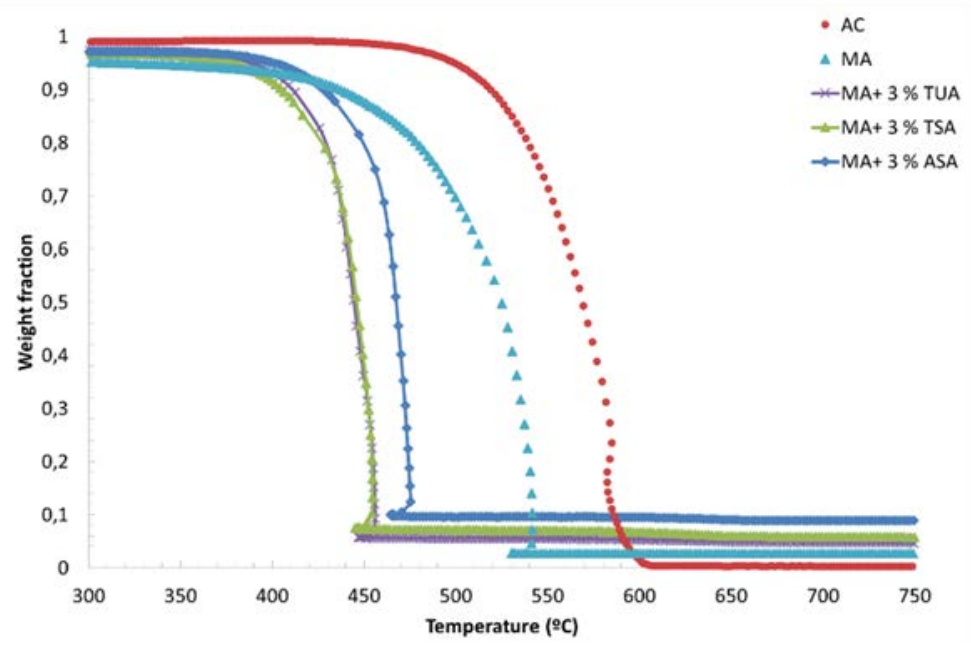

Fig. 3. Comparison of TG runs of the different materials performed at $5{ }^{\circ} \mathrm{C} / \mathrm{min}$ in synthetic air.

193 Fig. 3 also shows the results of the runs performed by mixing MA with 3 wt.\% of TUA, TSA and ASA, 194 respectively. Surprisingly, with these mixtures, decomposition greatly accelerates, displacing the temperature 195 of the maximum decomposition rate at ca. $80-100{ }^{\circ} \mathrm{C}$. In this way, the main decomposition step is produced within the temperature range of $430-480{ }^{\circ} \mathrm{C}$. MA with 3 wt.\% of TUA and MA with 3 wt.\% of TSA present similar results, however ASA seems to have a less significant effect on decomposition. These results agree with the decomposition of pure inhibitor compounds shown in Fig. 1. TUA and TSA decompose within the temperature range of $200-300{ }^{\circ} \mathrm{C}$, but ASA decomposition takes place at a higher temperature, so this may be why ASA is less reactive.

In a previous study (Wang et al., 2005), the effect of amino compounds on the decomposition of carbon and model fly ash was reported. The authors showed that ammonia-containing inhibitors react with $\mathrm{CuCl}_{2}$, leading to an additional step in the decomposition curve; the authors, however, did not find any change in the decomposition temperature of the carbonaceous material when comparing MA with MA mixed with inhibitors. Fujimori et al. (2016) showed that TUA decomposes at $200-300{ }^{\circ} \mathrm{C}$, forming $\mathrm{NH}_{3}$. This ammonia can later react with $\mathrm{CuCl}_{2}$ eliminating the chlorination agent and decreasing the chlorinated species formed. In 
207 the case of sulphur compounds, the $\mathrm{SO}_{2}$ produced can react with $\mathrm{Cl}_{2}$ to form $\mathrm{SO}_{3}$ and $\mathrm{HCl}$ that are much less 208 reactive in the de-novo synthesis (Zhang et al., 2017).

209 Different authors have pointed out that during the decomposition of carbon in the presence of chlorine, pre210 treating the surfaces with diatomic chlorine stabilizes the material, increasing the stabilization effect with the 211 pre-treatment temperature (Evans et al., 1998). This stabilization occurs if no metal is present. Conversely, the 212 presence of transition metals, such as copper, accelerates the incorporation of chlorine in the carbonaceous 213 structure, but also the subsequent formation of volatile chlorinated compounds, leading to a weight loss at 214 lower temperature. In this way, the presence of $\mathrm{CuCl}_{2}$ in the $\mathrm{MA}$ sample accelerates carbon combustion, but 215 the emitted volatiles are most certainly mainly chlorinated. According to the literature (Evans et al., 1998), the 216 decomposition of chlorinated carbon without the presence of metal takes place at a higher temperature.

217 When the inhibitors are added to the MA, thermal decomposition further accelerates (i.e. the curves are found 218 at lower temperatures compared to the MA curve). Chen et al. (2014) indicated that there was a possible 219 reaction between carbonaceous material in the MA and sulfur or nitrogen present in the gases at $350{ }^{\circ} \mathrm{C}$. These 220 authors found that part of the chlorine in the MA was carried away and replaced by sulfur, implying that 221 eliminating chlorine may be a part of the inhibition mechanism. The detection of HCN in the gas phase 222 confirmed the reaction between $\mathrm{C}$ and $\mathrm{N}$. The reaction of the sulfur (or nitrogen) with the carbonaceous matrix 223 may explain the acceleration of the processes found in the present study. Zhan et al.(2016c) suggested that the 224 poisoning of the metal and the blocking of the chlorination were most probably responsible for the suppression mechanism. If only a poisoning (or blocking) of the metal is being produced, the decomposition 226 curves of MA impregnated with TUA, TSA or ASA would be at a higher temperature compared to the curves 227 corresponding to MA. The experimental curves, however, are above those obtained with MA.

\section{3.3. Kinetic study}

229 As mentioned above, a kinetic study was performed on the oxidative decomposition of the different samples: AC, MA, MA + 3 wt.\% TUA, MA + 3 wt. $\%$ TSA and MA + 3 wt.\% ASA. Fig. 2 shows the decomposition runs carried out at three different heating rates to obtain a detailed kinetic analysis. 
232 The kinetic model proposed for the oxidative decomposition of the carbonaceous structure consisted of a 233 single reaction of $\mathrm{n}^{\text {th }}$ order. Its kinetic equation can be expressed as follows:

$$
\mathrm{d} \square \square \mathrm{dt}=\square \square\left(\square \square \mathrm{Wc}_{\mathrm{wc})}\right) \square \square
$$

where ' $\mathrm{w}_{\mathrm{c}}$ ' is the mass fraction (mass of the solid at any time divided by the initial mass), ' $\mathrm{w}_{\mathrm{c} \infty}$ ' is the mass fraction at time infinity, which corresponds to the final residue of the experimental runs, ' $\mathrm{n}_{\mathrm{c}}$ ' is the reaction order and ' $\mathrm{k}_{\mathrm{c}}$ ' is the kinetic constant which follows the Arrhenius equation:

$$
\mathrm{k} \_=\mathrm{kc0exp}-\mathrm{EcRT}
$$

where ' $\mathrm{k}_{\mathrm{c} 0}$ ' is the pre-exponential factor $\left(\mathrm{s}^{-1}\right)$, ' $\mathrm{E}_{\mathrm{c}}$ ' is the activation energy $\left(\mathrm{KJ} \mathrm{mol}^{-1}\right)$, ' $\mathrm{R}$ ' is the gas constant $\left(\mathrm{KJ} \mathrm{mol}^{-1} \mathrm{~K}^{-1}\right)$ and ' $\mathrm{T}$ ' is the temperature $(\mathrm{K})$.

As previously shown, another reaction exists when the inhibitors are present, corresponding to the degradation of the carbonaceous structure by reaction with $\mathrm{S}$ - and $\mathrm{N}$-containing species. This $\mathrm{S} / \mathrm{N}$ reaction has also been modelled using an nth order kinetic law, in such a way that the dw/dt presents an equation law equivalent to that presented for carbon decomposition:

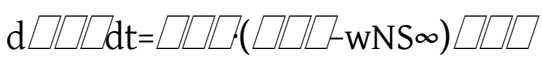

where subindex 'NS' refers to the reaction of the carbonaceous structure with $\mathrm{N}$ and/or $\mathrm{S}$ species. When the material undergoes both processes:

where ' $\alpha_{\mathrm{c} 0}$ ' represents the importance of the first reaction vs. total weight loss. For the optimization of the TG runs (at all the heating rates considered), activation energies $\left(E_{C}\right.$ and $\left.E_{N S}\right)$ and reaction orders were equal for all the materials tested. This was done to simplify calculating the kinetic constants and was based on the fact that the presence of $\mathrm{CuCl}_{2}$ and the different inhibitors would affect the value of $\mathrm{k}_{0}$ in the Arrhenius expression. The optimization was performed by integrating the differential equations presented in the kinetic model by means of the Runge-Kutta $4^{\text {th }}$ order method, considering and testing that the intervals of time were small enough to make the integration errors negligible. The optimization method of the Solver function in a 
264 weight loss and their derivatives. The objective function (OF) to minimize was the sum of the square

265 differences between the derivative of the experimental and calculated mass loss:

where 'p' represents the experimental data at time ' $t$ ' in the experiment at heating rate ' $m$ '. Worthy of note, with this methodology, a unique set of kinetic constants is calculated from the experimental curves obtained at the different heating rates, and it provides kinetic constant values that are valid for the whole set of heating rates used. This OF has been used in previous studies with satisfactory results (Conesa et al., 2015; Conesa and Soler, 2017).

The results of the optimization are shown in Table 1. The calculated curves are shown in Fig. SM1 to SM5 in the Supplementary Material, where the experimental curves are also presented for comparison purposes. Better fittings were obtained when allowing the order of the reaction and activation energies to vary, presenting a minimum in the OF for an order close to 0.6. As observed in Fig. SM1 to SM5, the fittings obtained describe the behaviour of combustion runs for each sample satisfactorily, since the experimental and calculated curves are very similar. If the activation energies and the reaction order could vary, the fitting would naturally improve, but the improvement obtained in this case would not be important enough to justify the introduction of more parameters in the model.

\begin{tabular}{|c|c|c|c|c|c|}
\cline { 2 - 6 } \multicolumn{1}{c|}{} & AC & MA & MA + 3 \% TUA & MA + 3 \% ASA & MA + 3 \% TSA \\
\hline $\mathbf{k}_{\mathbf{0}}\left(\mathbf{s}^{-\mathbf{1}}\right)$ & $3.12 \cdot 10^{8}$ & $1.38 \cdot 10^{9}$ & $1.49 \cdot 10^{10}$ & $8.25 \cdot 10^{9}$ & $1.60 \cdot 10^{10}$ \\
\hline $\mathbf{E}_{\mathbf{a}}(\mathbf{k J} / \mathbf{m o l})$ & \multicolumn{5}{|c|}{126.2} \\
\hline $\mathbf{w}_{\infty}$ & 0.011 & 0.006 & 0.021 & 0.006 & 0.018 \\
\hline $\mathbf{n}$ & \multicolumn{5}{|c}{0.60} \\
\hline
\end{tabular}

Table 1. Optimized parameters for the reaction of decomposition of the carbonaceous structure.

287 As shown in Table 1, the values of pre-exponential factors $\left(\mathrm{k}_{0}\right)$ follow the expected trend, as can be observed in Fig. 2. The value of $\mathrm{k}_{0}$ for MA is higher than for AC, i.e. MA decomposition is much faster than AC decomposition. In addition, the presence of the inhibitors accelerates the decomposition even further, in the following order: ASA $<\mathrm{TUA}<\mathrm{TSA}$. The value of this parameter can be related to the number of active sites in 

the carbon surface. Finally, $\mathrm{w}_{\infty}$ values represent the final residue in the TG curves and are in accordance with Fig. 2.

293

\subsection{Evolved gas analysis}

294 The decomposition runs were also carried out in a TG-MS in order to know the evolved gas species. Selected 295 ions of the main products expected were chosen, and special interest was given to the nitrogen and sulfur 296 compounds. Fig. 4 shows the evolution of the most important peaks, comparing all materials prepared in the 297 present study.
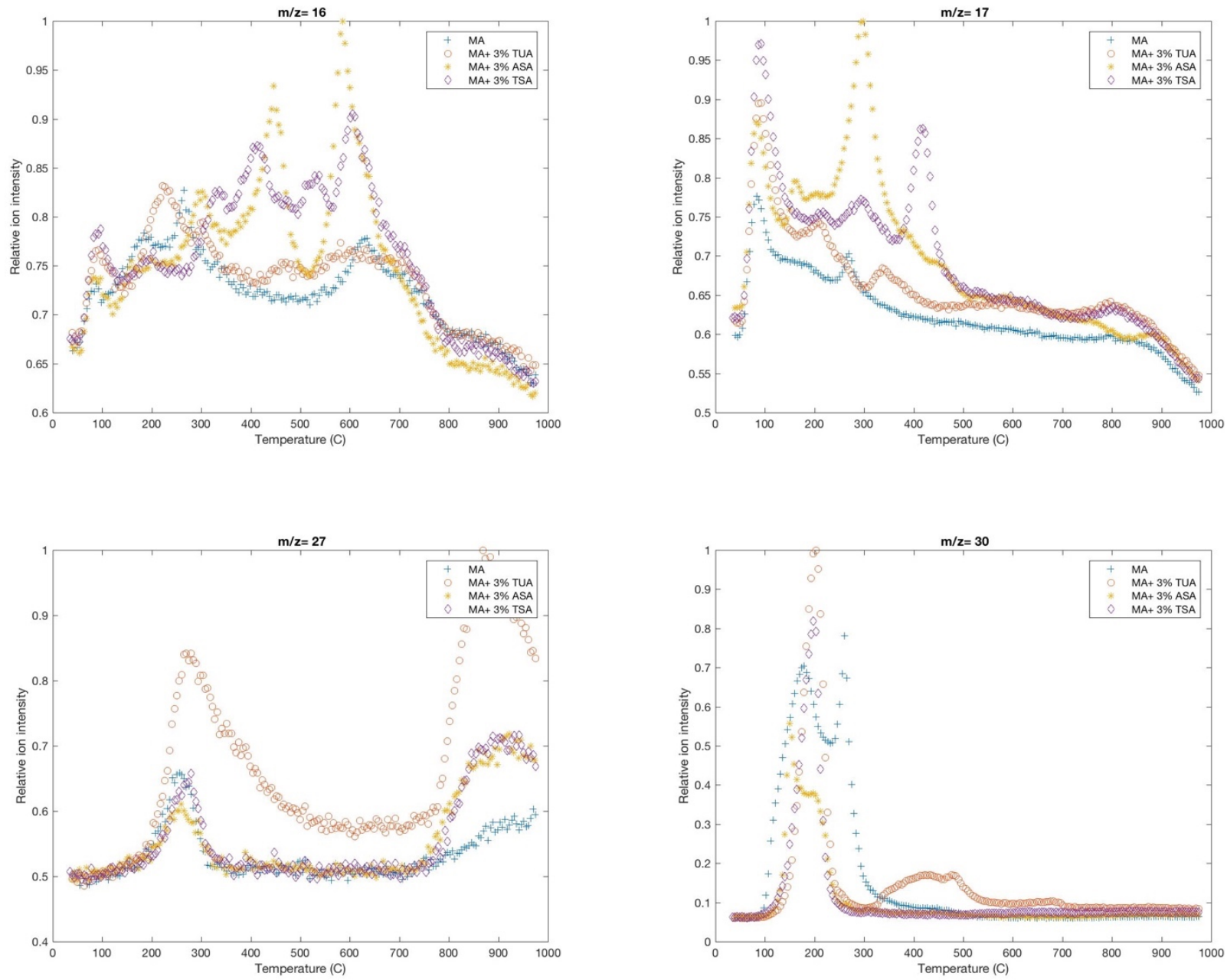

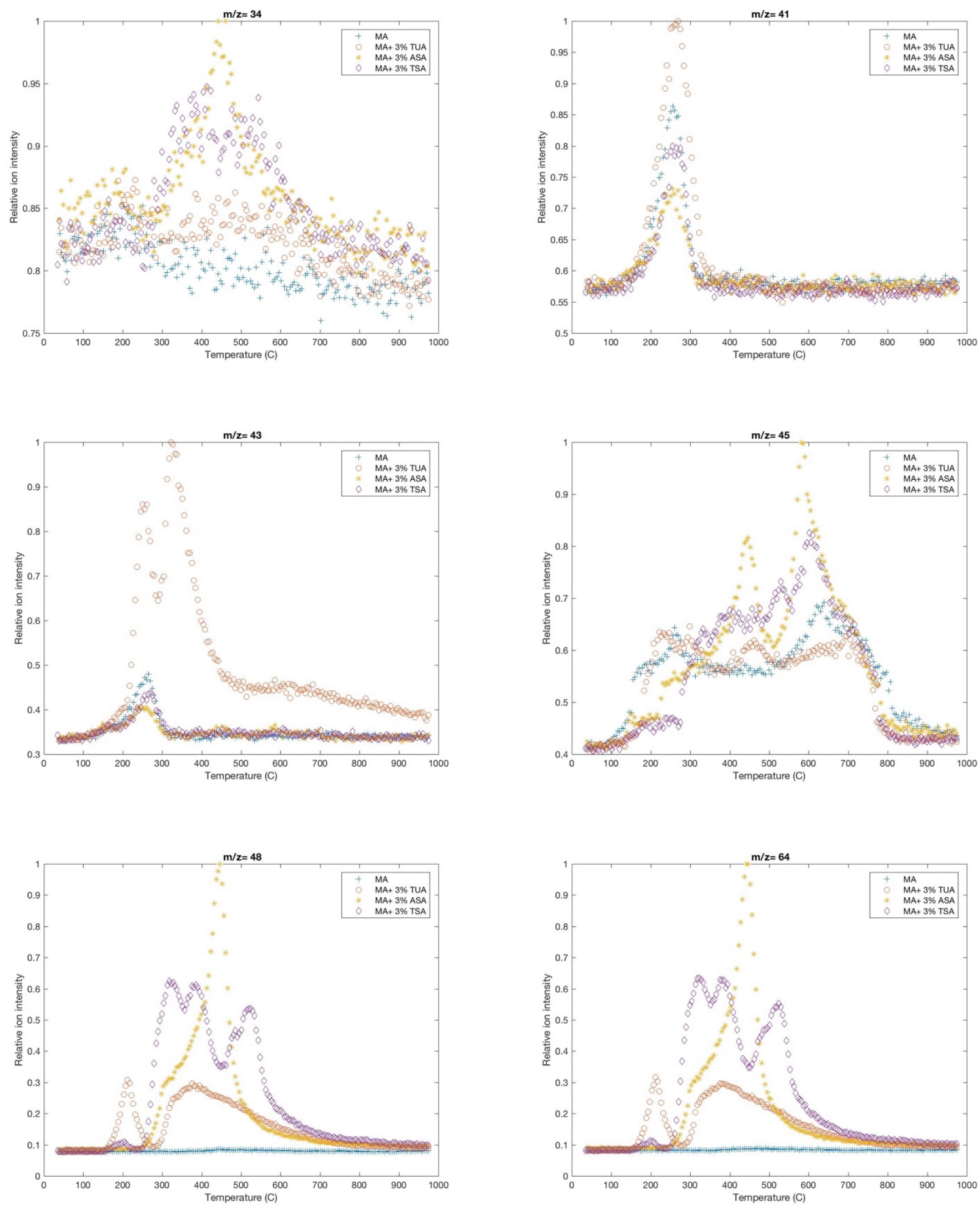

Fig. 4. TG-MS analysis of the main evolved gases for the model ash (MA) and the different mixtures (MA with 3 wt \% TUA, ASA and TSA, respectively) at $20^{\circ} \mathrm{C} / \mathrm{min}$ in synthetic air. 
Ion at $\mathrm{m} / \mathrm{z}=16$ (methane) shows a similar evolution in all the samples, being perhaps a little greater in the samples 'MA+3 wt.\% TSA' and 'MA+3 wt.\% ASA'. This can be related to the production not only of methane but of other aliphatic compounds (ethane, propane, etc....) as well. The signals at $\mathrm{m} / \mathrm{z}=17$ and $\mathrm{m} / \mathrm{z}=18$ (not shown) correspond to the decomposition of $\mathrm{NH}_{3}$ and water. The first peak in the curves (at $100{ }^{\circ} \mathrm{C}$ approx.) clearly corresponds to $\mathrm{H}_{2} \mathrm{O}$. Two other peaks can be observed. At approximately $300{ }^{\circ} \mathrm{C}$, the decomposition of MA in the presence of ASA presents a clear evolution of this peak and is of lower intensity in the case of the TSA and TUA impregnated samples. On the other hand, at $450{ }^{\circ} \mathrm{C}$, the sample with TSA presents a high peak. In a previous study, Fu et al. (2015) indicated that ammonium $\left(\mathrm{NH}_{4}{ }^{+}\right)$contained in TSA tended to inhibit PCDD/F formation when released in the form of $\mathrm{NH}_{3}$. More importantly, the signal was found at $\mathrm{m} / \mathrm{z}=27$, corresponding to $\mathrm{HCN}$. All samples presented this peak, but it was much weaker in the MA sample, and showed a very high intensity for the sample impregnated with 311 TUA. This would confirm the reaction of carbon with the nitrogenated compounds, producing HCN and avoiding the latter production of PCDD/F structures.

313 The production of NO could be observed at $\mathrm{m} / \mathrm{z}=30$. It was produced at temperatures below $300{ }^{\circ} \mathrm{C}$ for all the 314 samples studied, but the presence of TUA also produced a peak of NO centred around $450{ }^{\circ} \mathrm{C}$. The $\mathrm{m} / \mathrm{z}=41$ signal is related to this and corresponds to R-NO structures (nitriles); it was also present in all the runs.

316 Another important peak observed was $\mathrm{m} / \mathrm{z}=34$, caused by the presence of $\mathrm{H}_{2} \mathrm{~S}$. As previously pointed out, sulfur is able to react with the carbonaceous structure of the model ash, in this case producing hydrogen 318 sulfide. The signal was quite low in all runs, but we can assert that the decomposition of MA did not produce $319 \mathrm{H}_{2} \mathrm{~S}$ whereas a limited amount was formed in the presence of TUA, ASA or TSA.

320 The peak at $\mathrm{m} / \mathrm{z}=43$ could be due to the presence of CHNO, but it was surprisingly high in the presence of 321 TUA; thus, it is definitively mainly due to the presence of this latter compound, which presented a secondary 322 peak at this ion mass.

323 Mass ions at $\mathrm{m} / \mathrm{z}=44$ (not shown) and 45 (see Fig. 4) were similar and corresponded to either $\mathrm{CO}_{2}$ and/or 324 dimethylamine $\left(\mathrm{C}_{2} \mathrm{H}_{7} \mathrm{~N}\right)$. The relative intensities of the signals indicated that the latter option was the most probable. In any case, the evolution of these peaks presented two maxima, at ca. 450 and $680{ }^{\circ} \mathrm{C}$. 
326 Finally, $\mathrm{SO}(\mathrm{m} / \mathrm{z}=48)$ and $\mathrm{SO}_{2}(\mathrm{~m} / \mathrm{z}=64)$ evolved in a very similar way, presenting a nil amount in the MA 327 sample, and very high intensity in the presence of ASA and TUA.

\section{Conclusions}

329 After carrying out the thermal decomposition of all the samples in synthetic air in thermobalance, we can conclude that a potential reaction of the sulfur or the nitrogen to the carbonaceous matrix caused the acceleration of the thermal decomposition process, given that the decomposition of the mixtures (MA with 3 wt.\% TUA, MA with 3 wt.\% TSA and MA with 3 wt.\% ASA) occurred at a surprisingly much faster rate than the decomposition of MA. In this way, the main decomposition step for the mixtures was produced within the temperature range $430-480{ }^{\circ} \mathrm{C}$, leading to a reduction in temperature of the maximum decomposition rate of almost $80-100{ }^{\circ} \mathrm{C}$. The inhibitor compounds accelerated the thermal decomposition of carbonaceous material in this order: ASA $<$ TUA $<$ TSA. Therefore, TSA and TUA can be better inhibitor compounds than ASA. The emission of $\mathrm{HCN}, \mathrm{H}_{2} \mathrm{~S}$ and $\mathrm{SO}_{x}$ in the decomposition runs carried out in a TG-MS confirmed the possible reaction of the carbonaceous matrix with the $\mathrm{N}$ - and S- containing compounds, preventing the future production of chlorinated organic compounds.

\section{Acknowledgements}

341 This work was supported by the CTQ2016-76608-R project from the Ministry of Economy, Industry and Competitiveness (Spain), the PROMETEOII/2014/007 project of the Valencian Community Regional Government (Spain) and the UAUSTI17-07 grant from University of Alicante (Spain).

\section{References}

345 Baker, J.I., Hites, R.A., 2000. Is Combustion the Major Source of Polychlorinated Dibenzo-p-dioxins and 346 Dibenzofurans to the Environment? A Mass Balance Investigation. Environ. Sci. Technol. 34, 2879-2886.

347 Blumenthal, K., 2011. Generation and treatment of municipal waste Eurostat.

348 Caballero, J.A., Conesa, J.A., 2005. Mathematical considerations for nonisothermal kinetics in thermal 349 decomposition. J. Anal. Appl. Pyrol. 73, 85-100.

350 Conesa, J., Rey, L., 2015. Thermogravimetric and kinetic analysis of the decomposition of solid recovered 351 fuel from municipal solid waste. J. Therm. Anal. Calorim., 1-8. 
Conesa, J., Rey, L., Aracil, I., 2015. Modeling the thermal decomposition of automotive shredder residue. J.

353 Therm. Anal. Calorim., 1-11.

354 Conesa, J.A., Fullana, A., Font, R., 2001. Reactivity of carbonaceous materials modified by copper chloride 355 addition. A thermogravimetric study. J. Anal. Appl. Pyrol. 58-59, 553-568.

356 Conesa, J.A., Fullana, A., Font, R., 2002. De novo-synthesis of PCDD/Fs by thermogravimetry. Environ. Sci. 357

Technol. 36, 263-269.

Conesa, J.A., Soler, A., 2017. Decomposition kinetics of materials combining biomass and electronic waste. J. Therm. Anal. Calorim. 128, 225-233.

Chen, T., Zhan, M.-X., Lin, X.-Q., Li, X.-D., Lu, S.-Y., Yan, J.-H., Buekens, A., Cen, K.-F., 2014. Inhibition of the de novo synthesis of PCDD/Fs on model fly ash by sludge drying gases. Chemosphere 114, 226-232. Eurostat, 2010. Environmental statistics and accounts in Europe.

Eurostat, 2018. Municipal waste statistics.

Evans, M.J.B., Halliop, E., Liang, S., MacDonald, J.A.F., 1998. The effect of chlorination on surface properties of activated carbon. Carbon 36, 1677-1682.

Fu, J.-Y., Li, X.-D., Chen, T., Lin, X.-Q., Buekens, A., Lu, S.-Y., Yan, J.-H., Cen, K.-F., 2015. PCDD/Fs' suppression by sulfur-amine/ammonium compounds. Chemosphere 123, 9-16.

Fujimori, T., Nakamura, M., Takaoka, M., Shiota, K., Kitajima, Y., 2016. Synergetic inhibition of thermochemical formation of chlorinated aromatics by sulfur and nitrogen derived from thiourea: Multielement characterizations. J. Hazard. Mater. 311, 43-50.

Jedynska, A., Hoek, G., Eeftens, M., Cyrys, J., Keuken, M., Ampe, C., Beelen, R., Cesaroni, G., Forastiere, F., Cirach, M., de Hoogh, K., De Nazelle, A., Madsen, C., Declercq, C., Eriksen, K.T., Katsouyanni, K., Akhlaghi, H.M., Lanki, T., Meliefste, K., Nieuwenhuijsen, M., Oldenwening, M., Pennanen, A., RaaschouNielsen, O., Brunekreef, B., Kooter, I.M., 2014. Spatial variations of PAH, hopanes/steranes and EC/OC concentrations within and between European study areas. Atmos. Environ. 87, 239-248.

Ji, S.S., Li, X.D., Ren, Y., Chen, T., Cen, K.F., Ni, M.J., Buekens, A., 2013. Ozone-enhanced oxidation of PCDD/Fs over V2O5-TiO2-based catalyst. Chemosphere 92, 265-272. 
378 Kuzuhara, S., Sato, H., Tsubouchi, N., Ohtsuka, Y., Kasai, E., 2005. Effect of nitrogen-containing compounds 379 on polychlorinated dibenzo-p-dioxin/dibenzofuran formation through de novo synthesis. Environ. Sci. 380 Technol. 39, 795-799.

381 Laden, F., Neas, L.M., Dockery, D.W., Schwartz, J., 2000. Association of fine particulate matter from 382 different sources with daily mortality in six U.S. cities. Environ. Health Perspect. 108, 941-947.

383 Liu Ke-wei, C.T.-l., 2002. Studies on the thermal decomposition of ammonium sulfate. Chemical Research 384 and Application (in Chinese) 14 (6).

385 Lu, S.-y., Wang, Q.-l., Buekens, A.G., Yan, J.-h., Li, X.-d., Cen, K.-f., 2012. Photocatalytic decomposition of 386 gaseous 1,2-dichlorobenzene on TiO2 films: Effect of ozone addition. Chem. Eng. J. 195, 233-240.

387 Lu, S.-y., Wu, D., Wang, Q.-l., Yan, J., Buekens, A.G., Cen, K.-f., 2011. Photocatalytic decomposition on 388 nano-TiO2: Destruction of chloroaromatic compounds. Chemosphere 82, 1215-1224.

389 Luijk, R., Akkerman, D.M., Slot, P., Olie, K., Kapteijn, F., 1994. Mechanism of formation of polychlorinated 390 391 dibenzo-p-dioxins and dibenzofurans in the catalyzed combustion of carbon. Environ. Sci. Technol. 28, 312321.

392 Morawska, L., Zhang, J., 2002. Combustion sources of particles. 1. Health relevance and source signatures. 393 Chemosphere 49, 1045-1058.

394 Ooi, T.C., Thompson, D., Anderson, D.R., Fisher, R., Fray, T., Zandi, M., 2011. The effect of charcoal 395 combustion on iron-ore sintering performance and emission of persistent organic pollutants. Combust. Flame $396 \quad 158,979-987$.

397 Ortuño, N., Conesa, J.A., Moltó, J., Font, R., 2014. De Novo Synthesis of Brominated Dioxins and Furans. 398 Environ. Sci. Technol. 48, 7959-7965.

399 Pandelova, M.E., Lenoir, D., Kettrup, A., Schramm, K.W., 2005. Primary measures for reduction of PCDD/F 400 in co-combustion of lignite coal and waste: Effect of various inhibitors. Environ. Sci. Technol. 39, 3345-3350. 401 Ricketts, B., Hotchkiss, R., Livingston, B., Hall, M., 2002. Technology Status Review of waste/Biomass Co402 Gasification with coal.

403 Ruokojärvi, P., Asikainen, A., Ruuskanen, J., Tuppurainen, K., Mueller, C., Kilpinen, P., Yli-Keturi, N., 2001. 404 Urea as a PCDD/F inhibitor in municipal waste incineration. J. Air Waste Manage. Assoc. 51, 422-431. 
Samaras, P., Blumenstock, M., Lenoir, D., Schramm, K.W., Kettrup, A., 2000. PCDD/F prevention by novel inhibitors: Addition of inorganic S- and N-compounds in the fuel before combustion. Environ. Sci. Technol. 34, 5092-5096.

408 Schwarz, G., Stieglitz, L., 1992. Formation of organohalogen compounds in fly ash by metal-catalyzed oxidation of residual carbon. Chemosphere 25, 277-282.

410 Stieglitz, L., 1998. Selected topics on the de novo synthesis of PCDD/PCDF on fly ash. Environmental 411 Engineering Science 15, 5-18.

412 Stieglitz, L., Zwick, G., Beck, J., Bautz, H., Roth, W., 1989a. Carbonaceous particles in fly ash -a source for 413 the de-novo-synthesis of organochlorocompounds. Chemosphere 19, 283-290.

414 Stieglitz, L., Zwick, G., Beck, J., Roth, W., Vogg, H., 1989b. On the de-novo synthesis of PCDD/PCDF on fly ash of municipal waste incinerators. Chemosphere 18, 1219-1226.

416 Tuppurainen, K., Halonen, I., Ruokojärvi, P., Tarhanen, J., Ruuskanen, J., 1998. Formation of PCDDs and 417 PCDFs in municipal waste incineration and its inhibition mechanisms: A review. Chemosphere 36, 14934181511.

419 US EPA, 1994. Method 5050. Bomb preparation method for solid waste. in: US EPA (Ed.). SW-846. United 420 States Environmental Protection Agency, Office of Solid Waste, Washington, D.C.

421 US EPA, 2000. Method 9056A. Determination of inorganic anions by ion chromatography. in: US EPA (Ed.). 422 SW-846. United States Environmental Protection Agency, Office of Solid Waste, Washington, D.C.

423 Vogg, H., Stieglitz, L., 1986. Thermal behavior of PCDD/PCDF in fly ash from municipal incinerators. 424 Chemosphere 15, 1373-1378.

425 Wang, S., Gao, Q., Wang, J., 2005. Thermodynamic analysis of decomposition of thiourea and thiourea 426 oxides. J. Phys. Chem. B 109, 17281-17289.

427 Wielgosiński, G., Namiecińska, O., Łechtańska, P., Grochowalski, A., 2016. Effect of selected additions on de 428 novo synthesis of polychlorinated dioxins and furans. Ecological Chemistry and Engineering S 23, 249-257. 429 Zhan, M.-X., Chen, T., Fu, J.-Y., Lin, X.-Q., Lu, S.-Y., Li, X.-D., Yan, J.-H., Buekens, A., 2016a. High 430 temperature suppression of dioxins. Chemosphere 146, 182-188.

431 Zhan, M.-X., Chen, T., Fu, J.-Y., Lin, X.-Q., Lu, S.-Y., Li, X.-D., Yan, J.-H., Buekens, A., 2016b. High 432 temperature suppression of dioxins. Chemosphere 146, 182-188. 
433 Zhan, M., Chen, T., Lin, X., Fu, J., Li, X., Yan, J., Buekens, A., 2016c. Suppression of dioxins after the post434 combustion zone of MSWIs. Waste Manage. 54, 153-161.

435 Zhang, M., Buekens, A., Li, X., 2017. Dioxins from Biomass Combustion: An Overview. Waste and Biomass 436 Valorization 8, 1-20.

437

438 